\title{
EDUCAÇÃO, CONSCIÊNCIA DE CLASSE E ESTRATÉGIA REVOLUCIONÁRIA ${ }^{1}$
}

\section{Mauro Luis lasi ${ }^{2}$}

Ficaria contente em debater o tema da educação com uma plenária tão grande como esta presente no $V$ EBEM. Ficaria ainda mais contente em debater o marxismo com uma plenária como esta. Portanto, é compreensível o meu entusiasmo diante da possibilidade de debater marxismo e educação nesta oportunidade. Tanta gente assim disposta a enfrentar este debate é sinal de mudanças importantes nestes tristes tempos, em suma, uma boa notícia.

Agora vamos às más notícias. Se vocês entenderam a mesa sobre a conjuntura política e o momento profundo de fragmentação em que se encontra a esquerda, devem ter percebido que estamos em apuros. Uma pergunta diante deste quadro torna-se essencial: Por que a classe trabalhadora aceita como suas propostas políticas que são contrárias as de seus interesses? Por que ao invés de se mobilizar por suas próprias demandas, aceita ser dirigida no caminho da passividade e do acomodamento. Por quê?

Comecemos por uma notícia publicada ainda no contexto da campanha eleitoral de 2010. O então candidato a Vice-Presidente da República, Michel Temer, ao falar para uma platéia de investidores estrangeiros dizia o seguinte:

Falo de um Brasil internamente pacificado. Se os movimentos sociais não estivesses pacificados, se os setores políticos não estivessem pacificados (...) se aqueles mais pobres não estivessem pacificados (...) isto geraria uma insegurança. (Folha de São Paulo, 27 de agosto de 2010, caderno A, p. 8)

Diante desta "pacificação social" ainda segundo o vice presidente de Dilma, o país se torna seguro para os investimentos. Estamos pacificados. 0 que temos que responder é qual a base dessa pacificação. Afinal de contas o que aconteceu?

Resistimos contra a Ditadura empresarial-militar que se implantou em 1964. A classe trabalhadora entra em cena no final dos anos 70 fazendo

\footnotetext{
1 Baseado na exposição realizada na mesa de mesmo nome no $V$ EBEM (Encontro Brasileiro de Educação e Marxismo) em abril de 2011, na UFSC em Florianópolis, publicado pela primeira vez na Revista Universidade e Sociedade, n 48, ano XXI, julho de 2011, ANDES, p. 122-130.

2 Professor adjunto da ESS da UFRJ. Pesquisador do NEPEM (Núcleo de estudos e pesquisas marxistas), do CC do PCB, do NEP 13 de Maio (Núcleo de Educação Popular 13 de Maio). Presidente da ADUFRJ.
} 
greves gloriosas que unificam os seus interesses apresentando-se com autonomia e independência frente aos patrões e ao Estado, tornando-se o principal ator da derrubada da Ditadura e do processo de democratização.

Chegamos na Constituição de 1988 em uma correlação de forças que permitiu expressar no texto legal uma série de demandas que naquele momento se apresentavam como acúmulo da luta por educação, saúde, direitos previdenciários e outros.

Hoje estamos falando aqui de uma pacificação, de uma apatia, de elogios ao crescimento econômico capitalista como a maneira consensual entre as classes para desenvolver o país e resolver seus velhos problemas sociais. Algo deu errado. O que?

Parece-me que a categoria essencial para compreender o movimento da consciência da classe trabalhadora e seu atual momento de impasse é a categoria de ideologia. Nós vamos ter que voltar a ela antes de pensar o tema da consciência, das alternativas revolucionárias e suas estratégias e o papel da educação dentro disso.

Por muito tempo compreendemos ideologia simplesmente como um conjunto de idéias. Os trabalhadores se amoldam a essas idéias porque sofrem uma imposição por parte da classe dominante de maneira que acabam por constituir sua visão de mundo a partir de idéias, valores, formas de pensar a si mesmo e ao mundo, que Ihes são impostas coercitivamente por seus adversários.

Marx e Engels (2007), em sua obra $A$ ideologia alemã, chegam a formular o seguinte argumento: é natural que os membros da classe dominante, que por serem dominantes detêm os meios de produção, controlem também os meios de produção e disseminação do conhecimento fazendo com que suas idéias sejam apresentadas como universais.

De fato isto se dá. Todos nós conhecemos a importância de controlar os centros de produção disseminação do conhecimento, por exemplo, as universidades, o mercado editorial, os centros de formação, de pesquisas e de desenvolvimento de tecnologias, ou, ainda, demarcar o campo de possibilidades e a forma da divulgação e disseminação do conhecimento acumulado nos aparelhos escolares. 
Estou longe de questionar esse fato, mas acredito que isso explica em parte o processo. Explica evidentemente o poder de uma classe em apresentar sua visão de mundo como sendo universal e reproduzir isso no conjunto da sociedade, mas, entretanto, não explica por que os trabalhadores explorados nessa ordem aceitam como suas, as idéias de seus adversários.

Reich (1974) pesquisando sobre a força do fascismo dizia: O que é difícil explicar não é porque alguém rouba, o difícil é explicar porque a maioria nas condições em que se encontra não o faz.

Parafraseando Reich, o que devemos hoje explicar não é porque que as pessoas se rebelam contra a ordem do capital, o que é, de certa forma, simples; mas por que a maioria não o faz e se submete passivamente à ordem que a mantêm na exploração.

A ordem do capital nunca deixou de nos ajudar no trabalho da consciência. Ela é injusta, desigual, fundada na exploração, na desumanização, destrói qualquer capacidade da vida se expressar como vida sendo fácil entender por que as pessoas se antagonizam contra a exploração e a reificação. Por outro lado, não é fácil entender por que a maioria mantêm-se passiva diante deste antagonismo da ordem do capital em relação à vida. Não pode ser somente pela reprodução e imposição de idéias, valores e conceitos prontos.

Caso restringíssemos a explicação até o que foi exposto, corremos o risco de aceitar como fundamento de nossa tese não os pressupostos marxianos, mas outra formulação, a de Emile Durkheim (1976), que acreditava que a consciência era formulada pela imposição coercitiva das forma de ser, pensar e agir. Não por acaso, para este pensador a educação encontrava-se no centro deste processo que ele entedia como positivo e saudável.

Creio que nós podemos ser induzidos a um erro ao compreender o fenômeno da ideologia dessa maneira, ou seja, acabamos por pensar a sua superação como a mera contraposição de um novo conjunto de idéias e valores.

Caso a ideologia fosse apenas um conjunto de valores e idéias que nos são impostas coercitivamente pelos aparatos de produção e disseminação do conhecimento e, portanto, também pela educação, a resposta seria contrapor a 
essa educação, uma educação revolucionária pensada a partir de conteúdos e formas distintas da educação conservadora.

Não se trata de negar a necessidade de pensar e desenvolver formas pedagógicas inovadoras e de realizar a batalha das idéias. O problema é que este caminho, louvável e necessário, pode nos levar a um impasse. Vejamos porque.

A pista para uma visão mais complexa e profunda para compreender o fenômeno da consciência está nas próprias formulações marxianas e engelsianas presentes na Ideologia alemã.

Dizem os autores:

As idéias dominantes não são nada mais do que a expressão ideal (ideológica) das relações materiais dominantes apreendidas como idéias; portanto, são a expressão das relações que fazem de uma classe a classe dominante, são as idéias de sua dominação (MARX; ENGELS, 2007, p. 47).

Notem que a dialética materialista tomou conta dos autores. Não se trata apenas de um conjunto de idéias que se impõem como dominantes. Elas são dominantes porque são da classe dominante, mas a classe só é dominante porque se insere em relações sociais de produção historicamente determinadas que as colocam no papel de dominação. Ora, a tarefa ficou mais difícil porque se as idéias que constituem uma ideologia são expressões das relações de dominação a superação delas pressupõe a superação destas relações e como Marx e Engels concluirão na mesma obra, isso pressupõe um “movimento prático, uma revolução" (MARX; ENGELS, 2007, p. 42).

O paradoxo é que se esse caminho nos ajuda a compreender melhor 0 fenômeno pode nos levar a um outro impasse, caindo em uma linearidade tão positivista quanto a primeira.

Concordando que cabe mudar as estruturas, as relações sociais de produção que são a base real da expressão ideológica, qual seria o papel da educação, seja ela pensada no campo da educação formal ou no contexto de práticas alternativas? Nenhum?

Caso não nos permitamos pensar dialeticamente a mudança da educação seria conseqüência da mudança social, mas a mudança social não poderia ser pensada como fator de alterações no processo educativo. 
Nesta concepção o que deveriam fazer os educadores revolucionários? Ora, fazer a revolução e não perder tempo na busca de formas e conteúdos de uma educação revolucionária, a não ser como mera agitação da necessidade da revolução.

Tentando resgatar a dialética de seu exílio para que ela possa nos ajudar na compreensão dessas polaridades de maneira menos mecânica, teríamos que pensar de forma um pouco distinta. A consciência só pode se originar e se desenvolver como expressão de relações que constituem o fundamento da sociabilidade humana, isto é, ela não é uma força que se impõe ao humano como a Idéia hegeliana ou sua expressão no Espírito objetivo ou no Espírito Absoluto. Assim, não nos espanta que a forma imediata da consciência da classe trabalhadora seja a expressão da mesma consciência da burguesia. Por quê?

Porque o proletariado não vive em outras relações. Ele vive nas relações constitutivas do capital. Portanto, a primeira expressão de uma consciência social, que os trabalhadores tomam como sua, é a expressão das relações que eles compartilham com a burguesia na existência mesma da sociedade capitalista.

Podemos afirmar, portanto, que a primeira expressão da consciência dos trabalhadores é a consciência burguesa. Eles pensam o mundo e a si mesmos a partir dos elementos que constituem a consciência da burguesia, portanto, não nos espanta que a primeira expressão prática dessa forma de consciência seja o amoldamento dos trabalhadores à sociedade da qual eles fazem parte e não sua negação.

A pergunta, então, passa a ser outra: como é possível superar este amoldamento uma vez que estamos condenados a partilhar com nosso adversário de classe a mesma base material que constituem o fundamento de nossa consciência social?

É, no entanto, este mesmo fato que permite a possibilidade dos trabalhadores irem além de sua consciência imediata. A sociabilidade que estamos inseridos é cindida em interesses de classe opostos, antagônicos e irreconciliáveis. Tem gente que ainda acredita que não se trata de um antagonismo irreconciliável, ou seja, acredita na possibilidade de conciliação entre as classes. 
Vejamos porque são inconciliáveis. A sociedade é dividida entre aqueles que apropriaram os meios de produção, contratam a força de trabalho, extraem mais valia, acumulam privadamente a riqueza socialmente produzida. De outro lado estamos nós, expropriados dos meios que nos permitem produzir os bens que satisfaçam nossas necessidades. Que tipo de acordo que podemos ter com eles? Talvez poupá-los fisicamente, caso eles se disponham a devolver os meios de produção que são de fato nossos. Este é o único acordo possível.

A contradição no âmbito do real se expressa na possibilidade de uma contradição no momento da consciência, de forma que podemos falar da possibilidade de uma consciência de classe própria de cada segmento que personifica estes interesses distintos. Aqui se apresenta outro risco. Há um viés sociológico que tenta entender a consciência de classe como forma de pensamento típico de cada classe, ou seja, a partir de que valores pensam e agem os trabalhadores, ou a partir de que valores pensam e agem a burguesia, ou os camponeses, ou a pequena burguesia e assim por diante, numa clara aproximação em relação ao universo da sociologia compreensiva de Weber (1979) e, no limite, um problema antropológico que permitiria ao pesquisador ir até a classe trabalhadora como Levi-Strauss diante dos trobriandeses.

O problema é que desta forma se torna impossível compreender o ser da classe e sua consciência. O ser da classe é um ser em movimento, ceifado de contradições e seu processo de consciência também, que só pode ser compreendido no interior da totalidade de suas relações e não isoladamente.

Dissemos que a primeira expressão da consciência é a do amoldamento, é a consciência da ordem da qual os trabalhadores fazem parte, expressando aquilo que Marx em seus primeiro textos largamente analisou como o fenômeno da alienação.

Em um outro momento vemos os trabalhadores se revoltando, entrando em luta, reivindicando suas demandas imediatas, aqui e ali explodindo em formas mais avançadas de luta contra a ordem capitalista. Em situações mais precisas e raras podemos ver os trabalhadores, levantando-se em movimentos históricos significativos, rompendo a ordem burguesa, ousando ir além dela, derrubando o estado burguês, iniciando experiências socialistas.

Diante deste movimento as pessoas se perguntam: qual é, então, a verdadeira essência da consciência da classe? 
Aqueles que acham que a verdadeira essência da consciência da classe está no amoldamento chegarão a uma conclusão espantosa que infelizmente entre nós foi apresentada por alguém que tem uma longa ficha de serviços prestados ao marxismo brasileiro: Jacob Gorender.

Gorender (1999) chegou numa conclusão espantosa: analisando bem as coisas a classe trabalhadora é ontologicamente reformista. Os trabalhadores realmente existentes querem viver, pagar suas contas, receber seu salário, ter sua casa, ter sua educação e se tudo der certo deixar de ser trabalhador.

Quando você chega para o trabalhador e fala: olha eu quero sociedade emancipada, sem classes, sem Estado, onde cada um possa pegar os bens produzidos de acordo com sua necessidade, o comunismo mundial, o trabalhador responde: muito bom, mas posso receber a minha parte agora em dinheiro?

Quer dizer que a consciência imediata é a consciência do ser inserido numa divisão social do trabalho, lutando na concorrência contra outros trabalhadores. Ora, se isso é a essência da consciência de classe dos trabalhadores, ela é, conclui o autor, ontologicamente reformista.

Consciência revolucionária seria expressão de uma pequena burguesia descontente, revoltada que cria uma teoria e atribuiu a esse proletariado real uma tese que não é dele.

O reverso desta tese, mas que acaba por se aparentar no fundamental à ela, se apresenta na afirmação segundo a qual os trabalhadores são em si mesmos revolucionários. O próprio Lukács (2005) no início das suas formulações marxistas acreditava nisso. O Lukács em Tática e Ética, numa passagem depois publicada em seu A história e consciência de classe, chega a falar o seguinte: todo trabalhador é, em si mesmo, um marxista ortodoxo. Evidente que há aqui um exagero.

Lógico que a posição de classes dos trabalhadores é essencial para a formação e desenvolvimento de sua consciência de classe como possibilidade objetiva e é isso que fala o marxista húngaro, mas isso não faz da consciência imediata do trabalhador sua consciência de classe, como o próprio Lukács bem sabe.

As duas teses, no entanto, se aproximam. Quem acredita que 0 proletariado é ontologicamente reformista, não consegue explicar os momentos 
de rebeldia e revolução. Quem acha que ele é ontologicamente revolucionário não consegue explicar porque que na maior parte do tempo ele não passa fazendo revoluções e rebeldia, mas sim acomodado a ordem.

Como podemos buscar uma solução para esse problema? Afirmando que os trabalhadores não são em si mesmo nem reformistas natos nem revolucionários por natureza. Da mesma forma, a consciência de classe dos trabalhadores não é nem ontologicamente revolucionária, nem reformista.

Estas manifestações são expressões do ser da classe trabalhadora, ou seja, a classe trabalhadora é ao mesmo tempo uma classe da ordem do capital e por isso expressa na sua consciência os elementos do amoldamento e exatamente por ser uma classe da ordem do capital pode entrar em choque com esta ordem almejando ir além dela, e quando o faz expressa uma consciência que pode chegar a uma consciência de classe.

Devemos resgatar Hegel e com ele afirmar que a verdade está no todo, mas o todo nada mais é do que o processo de sua constituição (HEGEL, 1997, p. 31).

Onde está, então, a consciência de classe? Ela esta no movimento que a leva da alienação inicial a rebeldia, a constituição das lutas imediatas, da possibilidade de constituição de um sujeito histórico. É esse movimento, nos termos de Marx tomando por empréstimo as palavras hegelianas, que leva da consciência em si à consciência para si.

Desta maneira, estamos agregando algo ao debate de nosso tema que não é estranho à Marx, mas que normalmente não é considerado. A consciência de classe dos trabalhadores está no movimento que a leva da consciência em si para a consciência para si, mas existe um momento anterior à própria consciência em si e que é a expressão mais imediata da consciência dos trabalhadores serializados na concorrência.

Dizem Marx e Engels (2007, p. 62): "a concorrência isola os indivíduos uns dos outros, não apenas os burgueses, mas ainda mais os proletários, apesar de agregá-los". Assim o mais correto seria dizer que o movimento da consciência da classe trabalhadora vai desde sua serialidade própria da concorrência, na qual a classe agregada pelo capital como classe se manifesta como uma pulverização de indivíduos submetidos à concorrência, como a própria burguesia, até o momento da luta contra o capital e da vivência das 
contradições desta forma particular de produção social da vida que torna possível que os trabalhadores se apresentem como uma classe, ainda nos limites de uma classe da ordem do capital (em si); para em um outro momento, como a potencialidade de ir além da ordem do capital (para si).

A compreensão do processo de consciência neste registro é que nos leva ao tema central de nossa reflexão. Esse movimento não é linear, nem evolutivo e nós no Brasil acreditamos que fosse.

Era uma vez uma classe toda dispersa, submetida às relações do capital, sob uma Ditadura, enfrentando situações concretas no arrocho, da intensificação do trabalho e daí as greves que eclodem no final dos anos 1970. Os trabalhadores entram em cena, se fundem como uma classe e exigem negociar com o capital as condições da sua vida no trabalho, conformam-se como uma classe na luta contra os patrões, criam organizações próprias que dão forma a este momento do ser da classe (em si) e ensaiam os germes de um sujeito histórico com independência de classe para apresentar um projeto societário contra o capital (para si) apontando para um projeto socialista, momento que não chegou a se completar.

É compreensível que muitos tenham imaginado tal processo de maneira linear e progressiva, tratava-se apenas de uma questão de tempo. Infelizmente as coisas não são tão simples. Tal trajetória, como todo movimento dialético é em espiral, avança por recuos, retoma patamares já superados, despenca para trás. Por quê?

Porque o processo de constituição da classe como classe, nos termos de Marx na Sagrada Família ou no Manifesto Comunista é um processo político, cortado pela luta de classes, portanto sujeito a toda dinâmica da luta de classe.

A classe se conforma em grande parte por aquilo que ela produz em cada momento do seu movimento histórico. Ocorre que não apenas a classe produz suas formas políticas organizativas, num certo momento essas formas uma vez produzidas agem sobre a classe e a constituem como classe em uma determinada direção.

Lênin, assim como Gramsci em outro momento afirmam que há momentos em que as massas avançam adiante dos partidos, mas há momentos em que os partidos têm obrigação de avançar além das massas. Ou 
seja, é fundamental que aprendamos com as massas o que fazer, mas é fundamental num certo momento que o partido diga às massas a direção a ser seguida dirigindo-as.

Lênin está pensando na revolução de 1905 na Rússia. Quando ele vai escrever os Ensinamentos da Insurreição de Moscou afirma que as massas foram além da estratégia traçada pela Social Democracia Russa e não param na greve geral.

Isso remete a dois elementos centrais do nosso tema e que foram tratados pelo mesmo Lênin ao refletir sobre a crise da II Internacional, as chamadas condições objetivas e subjetivas.

Quando nós entendemos equivocadamente a ideologia como mero conjunto de idéias que se impõe coercitivamente, o caminho para superá-la é a educação, ela seria o meio pelo qual eu posso arrancar os trabalhadores da alienação e trazê-los para a consciência de classe, para a luta e daí para a revolução.

No entanto, se estivermos certos em nossas análises sobre o processo de consciência (IASI, 2002; IASI, 2006; IASI, 2011), o primeiro questionamento é crise da forma de consciência imediata dos trabalhadores que se dá na vivência das contradições do real. No processo ideológico assumimos como nossos os valores burgueses pois estes são as expressões ideais das relações sociais de produção determinantes nas quais nos inserimos necessariamente e independente de nossas vontades. Se esse é o mecanismo originário da consciência imediata e igualmente útil para ideologia, ou seja, quando a ideologia dominante age sobre nós ela age sobre algo que a reconhece não é uma mera imposição de fora. Ela dialoga com as relações que são a sua própria base. Por isso para a cabeça das pessoas faz sentido.

Aliás, o que não faz sentido para elas é a nossa proposta. Todo mundo já tentou convencer uma pessoa submetida à alienação com a famosa exortação: Você aí parado, também é explorado! Ele balança a cabeça respeitosamente parecendo concordar e segue pensando exatamente como antes, pois está convencido de outra visão de mundo que faz muito mais sentido do que aquela que você está apresentando.

Ora, se isso é verdade a superação só pode se dar por uma contradição no campo dessa vivência, no campo da vivência das relações sociais. O que 
entra em contradição, em um primeiro momento no processo de consciência, são as idéias anteriormente introjetadas na vivência de um novo contexto material que se choca com os valores ideais próprias de outros contextos, como, por exemplo, se eu trabalhar vencerei na vida, no entanto, trabalho muito e a vida me venceu.

Algo tem que ser explicado. Essa contradição é uma passagem. É um ponto que permite ação vivida num primeiro momento individualmente como sina, como contradição do próprio indivíduo isolado, mas que em certas condições sociais das lutas históricas podem dar um salto significativo. Vivenciar essa contradição que julgava minha num contexto onde a percebo também nos outros. Isso permite a fusão (SARTRE, 1979). A formação do grupo inicial que ao se desenvolver pode levar uma consciência de classe em si.

No entanto, se é verdade que vivência das contradições move as pessoas para essa possibilidade, e as trajetórias vividas na situação de militância é a comprovação disso, não é verdade que ela, por si mesma, se desenvolve até uma consciência revolucionária.

Se é verdade, e é, que o movimento da consciência só pode brotar da vivência das contradições particulares, a compreensão da natureza dessas contradições não está nessa vivência da particularidade, na imediaticidade, não só por uma regra filosófica que afirma que o particular está no universal, mas o inverso não é válido, ou seja, o universal não está completamente no particular; mas porque se trata do campo da aparência, do campo da cotidianidade, do campo da superfície aonde as verdadeiras determinações não se expressam.

É neste momento que se torna essencial a teoria, o momento que nos permite compreender a profundidade da afirmação leniniana segundo a qual sem teoria revolucionária não há revolução. Trata-se de captar a totalidade como síntese de determinações complexas e não podemos encontrá-la no cotidiano e no âmbito da imediaticidade.

O paradoxo é que é exatamente aí, neste cotidiano, que se encontra a chave para a superação da alienação, pois é aí que as contradições entre os valores ideais se chocam em contradições com o real, mas isso não é suficiente. 
É a compreensão das determinações mais profundas, é a compreensão da totalidade que permite aos trabalhadores se ver como a classe histórica que são, compreender a natureza da forma capitalista e pensar a sua superação, pensando inclusive as vias de realização e as formas organizativas políticas necessárias.

O que devemos destacar é que isso tem que ser construído pela prática política da classe trabalhadora, é um esforço subjetivo da classe no seu caminho de emancipação.

Aqui ocorre, no entanto, uma inversão interessante.

É típico do ciclo que estamos encerrando aqui. Do mesmo modo que acreditamos que podemos produzir o salto da consciência através da educação, contrapondo novas idéias às velhas idéias, passamos a acreditar que as tarefas descritas, como a elaboração das estratégias, as vias revolucionárias e as formas organizativas a elas associadas são uma espécie de tarefa que a história resolve por nós. Vejam que interessante, nós queremos fazer o trabalho da história e esperamos que ela gentilmente faça o nosso.

Tem uma crise mundial e os marxistas todos vão para a janela e falam: Agora vai. Os trabalhadores olham para esquerda dividida e perguntam quando vamos nos unificar? Respondemos: depende da história.

O problema é que não depende. Depende da ação política da classe, da ação subjetiva da classe, da capacidade de se apropriar do instrumento teórico da classe, que acredito que é o marxismo, para compreender o real além de suas aparências, analisar as situações e contextos concretos numa perspectiva histórica e deles derivar nossos planos de luta e formas organizativas. Esse conjunto de tarefas cabe aos trabalhadores, não cabe a história.

Não me assusto com o apassivamento porque tenho certeza de que ele não é definitivo. Várias vezes na historia as pessoas chegaram a acreditar que a ordem finalmente havia neutralizado seu principal inimigo, seja pelo uso brutal da força, seja pelo poder ideológico de gerar "consentimento". Devemos lembrar de situações dramáticas como o nazismo ou de militantes revolucionários nos EUA na década de 1920, no auge da Socialdemocracia européia ou em outras situações limites.

É difícil viver em épocas de reação conservadora. Agora, não me assusto porque a dinâmica das relações capitalistas produzirá as condições em 
que a classe romperá esse véu enganador das aparências consensuais que tentar encobrir os antagonismos reais e classe reencontrará seu processo de luta (vejam as coisas como estão na Europa e nos EUA hoje em dia).

A ordem do capital continua fazendo seu trabalho. Ela vai nos explorar até provocar pontos de tensão de incompatibilização com a vida.

Agora no campo das condições subjetiva há um problema.

Porque se a gente formula uma proposta política errada, a gente molda ação da classe num sentido errado. Não se trata do desvio idealista que atribui ao o elemento teórico o poder decisivo que determina o sucesso ou fracasso de uma alternativa, mas de considerar que ele, nos termos de Engels (s/d[1890], p. 284) pode agir de maneira decisiva na determinação das formas das lutas em curso.

Se nós equivocamos na compreensão da formação social brasileira, traçamos estratégias equivocadas. Isso implica em desvios na forma como organizamos a classe para ação e os caminhos que indicamos para serem trilhados.

Por exemplo, a força hegemônica que dirige hoje a classe trabalhadora está convencida de que os problemas sociais se resolverão pelo desenvolvimento do capitalismo. Esta convencida que o socialismo foi reduzido a uma meta moral, um valor ligado à luta pela igualdade e contra injustiça e isso pode ser alcançado, segundo pensam estes senhores sobre o solo das atuais relações sociais de produção e as formas de propriedade próprias do modo de produção capitalista. Mais do que isto, os problemas e carências da classe trabalhadora são expressão do baixo desenvolvimento do capitalismo, portanto, seriam resolvidos pelas políticas de desenvolvimento.

Uma analise concreta de uma situação concreta, no entanto, nos levaria a outra constatação: o capitalismo completou-se no Brasil e no mundo.

Não temos educação, não temos saúde, temos várias formas de opressão, de desumanização, tudo virou mercadoria, e tudo isso não se dá por falta de capitalismo, nós temos essas carências por causa do desenvolvimento capitalista. Ora, essa constatação nos leva a uma conclusão: A estratégia já é uma estratégia socialista.

Agora qual é o grande problema quando cruzamos esta constatação com o tema da consciência. 
Podemos ter chegado à conclusão que a estratégia é socialista e a classe não. A classe está eufórica. A classe está consumindo porcarias políticas e eletrônicas. Nossa classe está convencida de que o capitalismo não é tão ruim assim, desde que eu ganhe o suficiente para pagar as prestações. Sua autonomia de classe foi quebrada, sua identidade moldada nos limites de uma cidadania burguesa, como consumidores, cindidos entre indivíduos privados na sociedade civil e cidadãos no Estado.

Há um abismo entre a consciência possível que chega à necessidade de superar capital e o sujeito que pode realizar essa superação.

Dois caminhos se apresentam neste momento. Ou você desiste e vira pós-moderno ou você vai até a classe e vai buscar as mediações políticas, educacionais e organizativas necessárias para construir o movimento no sentido dessa superação. Neste trabalho a educação formal e a não formal é essencial. Acredito, como Paulo Tumolo, que a educação formal é necessária, mas insuficiente.

É essencial que a classe crie seus próprios espaços formativos, por que não é verdade que o conhecimento considerado como neutro nos ajude em nossas tarefas pelo simples fato de ser conhecimento humano acumulado bastando socializá-lo. O conhecimento é revestido de ideologia, direcionado para uma funcionalidade de reprodução e garantia da ordem. Os trabalhadores, na imagem gramsciana devem fazer seu inventário, resgatar do conhecimento universal mais desenvolvido as bases para constituição de sua autonomia de classe, desvelando os fundamentos políticos e os interesses de classe que perpassam o conhecimento e as formas educativas e esta é uma tarefa que passa pela socialização do conhecimento nos espaços formais, mas exige que saibamos construir nossos próprios espaços formativos, pois certos temas e formas educativas exigem espaços próprios e independentes.

Nossa tarefa, então, é construir as mediações que permitam que a consciência como possibilidade objetiva de um sujeito histórico se transforme em força material e se apodere das massas elevando sua consciência imediata ao nível de uma consciência revolucionária, ou como afirmou Che Guevara, quando o extraordinário se torna cotidiano é a revolução. Mas, o que fazer numa circunstância onde percebemos a necessidade da revolução, ela não é possível? Preparar as condições, que o tornem possível. Eis nossa tarefa. 
Mas, os trabalhadores vão entender ou estamos separados pelo abismo de duas formas de consciência e duas linguagens estranhas entre si? Tentemos responder e encerrar com um pequeno poema de Bertold Brecht:

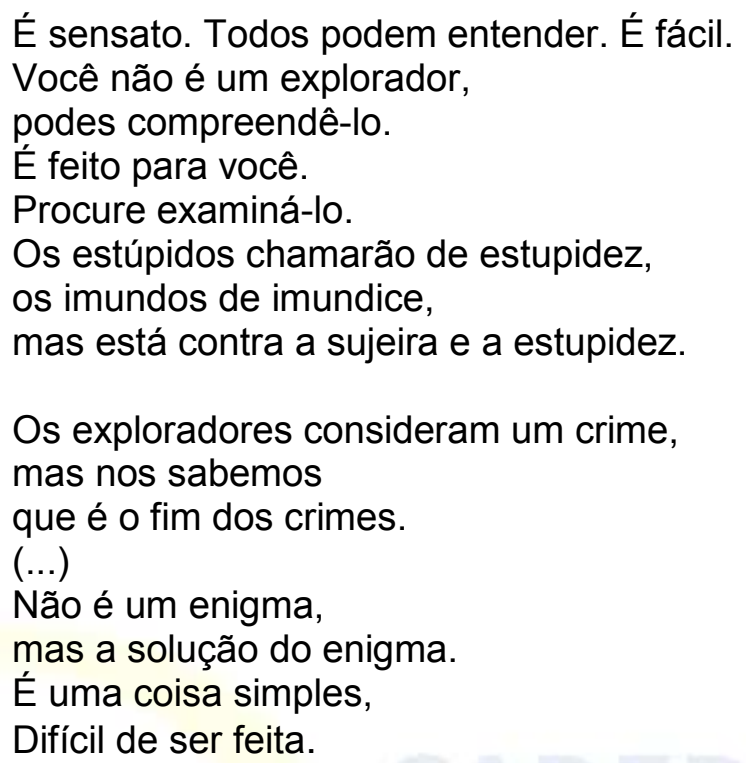

Florianópolis, abril de 2011.

\section{REFERÊNCIAS BIBLIOGRÁFICAS}

BRECHT, B. Antôlogia Poética. Rio de Janeiro: Elo, 1982.

DURKHEIM, E. As regras do método sociológico. São Paulo: Cia. Editora Nacional, 1976.

ENGELS, F. Carta a Bloch, setembro de 1890. In: ENGELS, F. Obras Escolhidas: volume III. São Paulo: Alfa-Ômega, [s/d].

GORENDER, J. Marxismo sem utopia. São Paulo: Ática, 1999.

HEGEL, G. W. F. A fenomenologia do espírito. Petrópolis: Vozes, 1997.

IASI, M. O dilema de Hamlet: o ser e o não ser da consciência. São Paulo: Viramundo, 2002.

Metamorfoses da consciência de classe: o PT entre a negação e o consentimento. São Paulo: Expressão Popular, 2004.

Ensaios sobre conscência e emancipação. 2a Edição. São Paulo: Expressão Popular, 2011. 
LUKÁCS, G. Táctica y ética: escritos tempranos (1919-1929). Buenos Aires: El cielo por asalto, 2005.

MARX, K.; ENGELS, F. A ideologia Alemã. São Paulo: Boitempo, 2007.

REICH, W. A psicologia de massas do fascismo. Porto: Escorpião, 1974.

SARTRE, J. P. Crítica de la razón dialectica. Buenos Aires: Lousada, 1979.

TUMOLO, P. S. Da contestação à confrmação: a formação sindical da CUT e a reestruturação capitalista. Campinas: Ed. Unicamp, 2002.

WEBER, M. Ensaios de Sociologia. Rio de Janeiro: Zahar, 1979. 